\title{
Bilateral breast metastasis as the first sign of recurrence of a cutaneous melanoma: A case report
}

\author{
Niyazi Karaman, Lütfi Doğan, Can Atalay, Cihangir Özaslan
}

Breast skin and parenchyma are metastatic sites for various tumours. Metastasis to the breast is rare, but it must be considered in the differential diagnosis of a breast mass. Melanoma is among the most commonly reported metastatic tumours of the breast. With the increasing incidence of melanoma, this complication is being encountered with greater frequency. Melanoma has different manifestations in the breast. All these manifestations are important not only as initial presentations of the disease, but also as indicators of the progression period of the disease. Along with a brief review of the literature, we report the case of a woman who presented with breast metastasis after 17 years as the first sign of recurrence of a melanoma. The aim of this study was to report the clinico-pathological features of a patient with metastatic melanoma to the breast. Metastasis can mimic either benign disease or primary malignancy and is often an unexpected diagnosis in a patient presenting with a breast mass. These masses generally indicate disseminated disease with very short survival. Metastasis should be suspected in patients with a breast mass and a prior history of melanoma even if the primary was removed a long time ago (17 years in our case). Fine needle aspiration cytology combined with immunohistochemistry is essential for the diagnosis of metastasis.

Key Words: Melanoma, metastasis, breast

Ankara Oncology Teaching Hospital, Department of General Surgery, Ankara, Turkey

This case presented as a poster presentation in 7. Congress of Balkan Union of Oncology (16-19 September, Izmir, Turkey)

Address for Correspondence Dr. Niyazi Karaman

Ankara Oncology Teaching Hospital, Department of General Surgery, Ankara, Turkey Phone: +903122251869 e-mail: niyazikaraman@hotmail.com

Received: 31.10 .2012

Accepted: 26.11.2012

Online Available Date: 09.07.2013

(c) Copyright 2013 by Turkish Surgical Association

Available online at www.ulusalcerrahidergisi.org

\section{INTRODUCTION}

Melanoma is the most increasing cancer worldwide and up to $20 \%$ develop metastatic disease $(1,2)$. Melanoma, which can arise from breast parenchyma or skin, can also be seen as metastasis to the parenchyme or intransit metastasis. Although breast metastasis is rare, melanoma is one of the most common primary sites in patients presenting with a breast lump. Primary breast skin melanoma accounts for less than $5 \%$ of primary skin melanomas and therefore there are no large series $(3,4)$. The treatment of melanoma is not different from the strategy elsewhere (5).

\section{CASE PRESENTATION}

A sixty-nine year old postmenopausal female presented with a well-defined, nodular $3 \times 2.5 \mathrm{~cm}$ mass located deep in the lower inner quadrant of the right breast and another similar $7 \mathrm{~mm}$ nodule in the upper lateral quadrant, in her annual screening mammography (MG). There were two nodules with regular borders of $2 \mathrm{~cm}$ and $5 \mathrm{~mm}$ size in the left breast.

Bilateral breast and axilla ultrasonography (US) showed a $18 \times 12 \mathrm{~mm}$ heterogenous hypoechoic lesion in the left breast, at 2 o'clock position $2 \mathrm{~cm}$ away from the areola, which had a peripheral hyperechogenic halo consistent with edema. There was also a $23 \times 20 \mathrm{~mm}$ cystic lesion in the right breast, at 3 o'clock position $5 \mathrm{~cm}$ away from the areola and another well-defined heterogenous hypoechoic lesion at 11 o'clock position $2 \mathrm{~cm}$ away from the areola. These findings were classified as Breast Imaging-Reporting and Data System: BI-RADS 4A and US guided FNA biopsy was performed from the previously described lesions. Pathology revealed positivity of protein S100, human melanoma black (HMB45) and vimentin, negative for tirosinase and melan A, with observation of atypical cells suggestive of metastatic melanoma. The lesion was negative for cytokeratin (CK) and epithelial membrane antigen (EMA) to exclude of the breast; and negative for Leukocyte Common Antigen (LCA) to exclude lymphoma.

It was found out in past medical history that 17 years ago she underwent wide excision and flap reconstruction for a melanoma in the left infraorbital area. The lesion had been staged as Clark level 4 and she had received no adjuvant therapy, and she was accepted as having complete remission.

A thorax computed tomography showed bilateral breast nodules up to $2.5 \mathrm{~cm}$ in size, and lymph nodes in the right axilla up to $3 \times 2 \mathrm{~cm}$ in size. There were no definitive metastatic lesions in the lungs. The ab- 
dominopelvic CT revealed a $6 \times 4 \mathrm{~cm}$ hypodense, heterogenous mass in the left adrenal gland with projections to the surrounding fat tissue, perirenal fascia and kidneys.

Image guided biopsy of the left adrenal was performed. Pathology evaluation revealed atypic cells positive for HMB45 and $\mathrm{S} 100$.

While the pathology results were being awaited, subcutaneous nodules in the right lomber and right forearm regions were developed. The patient was started on Temozalamide for systemic disease. The disease progressed under therapy and the patient died due to with complications related with metastasis.

\section{DISCUSSION}

Besides primary lesions of the breast, metastatic lesions can also be seen and these usually present as clinically benign diseases. Metastatic tumors of the breast are rare. Breast is an organ to which lung cancer, leukemia, or melanoma metastasize (6-13). Arora and Robinson (9) reported concomitant organ metastases in 15 patients with breast metastasis. There are reports of isolated breast metastases of skin sites other than the breast $(6-8,10,14)$.

In a series of 27 patients with skin melanoma metastasis to the breast, the mean age was 41 years and $82 \%$ of the patients had a primary lesion in the upper extremity. The period between primary tumor diagnosis time and metastasis was 52.5 months, and all patients had distant metastasis at the time of diagnosis and bilateral disease in five. The mean survival was 12.9 months (1).

MGandUS should evaluate the number of metastaticfociina patient with breast lump who have a history of skin melanoma (11). After FNA diagnosis, wide excision or quadranectomy is sufficient, given there are no other metastases $(6-8,10,14)$.

The prognosis in patients with isolated metastasis to the breast may have better prognosis than diffuse disease, therefore more caution should be exercised in these patients (15). If histopathology findings are not concordant with primary breast tumors, immunohistochemistry will play the leading role in diagnosis (16).

MD Anderson Cancer Center evaluated their series of solid tumors with breast metastasis and in 53,9\% have found an additional metastatic foci and the most frequent primary focus was melanoma (38.5\%). Seventy-seven percent of these patients were diagnosed with a mass in physical examination and the mean survival was around 10 months (0.4-192.7 months), and the mean age at diagnosis was 51 (13-85). In univariate analysis, the survival was better if there were no other metastatic sites, if it is a neuroendocrine tumor metastasis and if it was surgically resected. In multivariate analysis the death risk was $88 \%$ higher in patients not receiving surgery versus those who were operated. Individualized local therapies have been suggested because of the poor prognosis (17).

In another reported series including 24 patients with breast metastasis, the most common primary sites were melanoma and ovarian cancer. In this series, two patient's primary sites could not be identified. Solitary nodules were seen in 17 patients whereas multiple nodules were found in seven. Sixteen patients were lost with rapid progression of their disease (18).

The most common mammographic findings are well-defined masses with increased density not showing spicular projections (19). The duration between the primary lesion and metastasis varies between 0-108 months (mean 17 months). The mean survival after diagnosis of breast metastasis is reported as 23 months (0.2-144 months) (19). In a series where nine consecutive breast metastasis biopsies were evaluated the primary sites were ovary in 3 cases, melanoma in 2 cases and the endocervix, endometrium, lung and prostate in the rest. In these lesions especially with no cancer history cytopathology and immunohistochemistry evaluations are helpful (20).

FNA of the metastatic lesion is required in order to avoid an unnecessary mastectomy and to plan appropriate chemotherapy and radiotherapy. In a study where 1866 breast needle biopsies were evaluated metastatic tumors were found in 5 patients (1.5\%), two of which were melanoma (21).

The treatment of primary skin melanoma of the breast does not differ from the strategies for other sites. Wide local excision and sentinel lymph node biopsy is the standard of care. If axilla is involved lymph node dissection should be done. However, since survival in patients with breast metastasis of skin melanoma is poor, individualized local and systemic treatments should be planned.

\section{CONCLUSION}

Metastasis should be suspected in patients with breast lump and history of melanoma even though it was treated a long time ago. Fine needle biopsy and immunohistochemical evaluation is required for the diagnosis of the metastasis.

\section{Conflict of Interest}

No conflict of interest was declared by the authors.

Peer-review: Externally peer-reviewed.

\section{Author Contributions}

Study concept and design - N.K., C.Ö., C.A.; Acquisition of data - N.K., L.D.; Analysis and interpretation of data - N.K., C.Ö., C.A.; Preparation of the manuscript - N.K.

\section{REFERENCES}

1. Ravdel L, Robinson WA, Lewis K, Gonzalez R. Metastatic melanoma in the breast: a report of 27 cases. J Surg Oncol 2006; 94: 101-104. [CrossRef]

2. Sampedro Gimeno T, Moreno Antón F, López-Tarruella Cobo $S$, González Larriba JL, Furio Bacete V, Díaz-Rubio García E. Breast metastases as the first sign of recurrence of a cutaneous melanoma. Clin Transl Oncol 2006; 8: 57-59. [CrossRef]

3. Papachristou DN, Kinne DW, Rosen PP, Ashikari R, Fortner JG. Cutaneous melanoma of the breast. Surgery 1979; 85: 322-328.

4. Bono A, Baldi M, Maurichi A, Tomatis S. Distribution of melanoma on breast surface suggests its etiology. Int J Cancer 2003; 105: 434. [CrossRef] 
5. Gershenwald JE, Thompson W, Mansfield PF, Lee JE, Colome MI, Tseng $\mathrm{CH}$, et al. Multi-institutional melanoma lymphatic mapping experience: the prognostic value of sentinel lymph node status in 612 stage I or II melanoma patients. J Clin Oncol 1999; 17: 976-983.

6. Cangiarella J, Symmans WF, Cohen JM, Goldenberg A, Shapiro RL, Waisman J. Malignant melanoma metastatic to the breast: a report of seven cases diagnosed by fine-needle aspiration cytology. Cancer 1998; 84: 160-162. [CrossRef]

7. Deshpande AH, Munshi MM, Lele VR, Bobhate SK. Aspiration cytology of extramammary tumors metastatic to the breast. Diagn Cytopathol 1999; 21:319-323. [CrossRef]

8. Majeski J. Bilateral masses as initial presentation of widely metastatic melanoma. J Surg Oncol 1999; 72: 175-177. [CrossRef]

9. Arora R, Robinson W. Breast metastases from malignant melanoma. J Surg Oncol 1992; 50: 27-29. [CrossRef]

10. Plesnicar A, Kovac V. Breast metastases from cutaneous melanoma: a report of three cases. Tumori 2000; 86: 170-173.

11. Ho LW, Wong KP, Chan JH, Chow LW, Leung EY, Leong L. MR appearance of metastatic melanotic melanoma in the breast. Clin Radiol 2000; 55: 572-573. [CrossRef]

12. Padmore RF, Lara JF, Ackerman DJ, Gales T, Sigurdson ER, Ehya H, et al. Primary combined malignant melanoma and ductal carcinoma of the breast. A report of two cases. Cancer 1996; 78: 25152525. [CrossRef]

13. Kurul S. Diffuse microscopic in-transit metastases from malignant melanoma of the breast. Plast Reconstr Surg 2000; 106: 513-514. [CrossRef]
14. Mayayo Artal E, Gómez-Aracil V, Mayayo Alvira R, Azua-Romeo J, Arraiza A. Spindle cell malignant melanoma metastatic to the breast from a pigmented lesion on the back. A case report. Acta Cytol 2004; 48: 387-390. [CrossRef]

15. Kurul S, Taş F, Büyükbabani N, Mudun A, Baykal C, Camlica H. Different manifestations of malignant melanoma in the breast: a report of 12 cases and a review of the literature. Jpn J Clin Oncol 2005; 35: 202-206. [CrossRef]

16. Lee AH. The histological diagnosis of metastases to the breast from extramammary malignancies. J Clin Pathol 2007; 60: 13331341. [CrossRef]

17. Williams SA, Ehlers RA 2nd, Hunt KK, Yi M, Kuerer HM, Singletary $\mathrm{SE}$, et al. Metastases to the breast from nonbreast solid neoplasms: presentation and determinants of survival. Cancer 2007; 110: 731 737. [CrossRef]

18. Alvarado Cabrero I, Carrera Alvarez M, Pérez Montiel D, Tavassoli FA. Metastases to the breast. Eur J Surg Oncol 2003; 29: 854-855. [CrossRef]

19. Ribeiro-Silva A, Mendes CF, Costa IS, de Moura HB, Tiezzi DG, Andrade JM. Metastases to the breast from extramammary malignancies: a clinicopathologic study of 12 cases. Pol J Pathol 2006; 57: 161-165.

20. Fulciniti F, Losito S, Botti G, Di Mattia D, La Mura A, Pisano C, et al. Metastases to the breast: role of fine needle cytology samples. Our experience with nine cases in 2 years. Ann Oncol 2008; 19: 682-687. [CrossRef]

21. Handa U, Chhabra S, Mohan H. Aspiration cytology of extramammary tumours metastatic to the breast. Indian J Pathol Microbiol 2007; 50: 855-858. 